\title{
THE GENETICS OF B CHROMOSOMES IN MAIZE
}

\author{
D. G. CATCHESIDE \\ Department of Microbiology, University of Birmingham
}

Received 2.i.56

B chromosomes in maize, and B-A interchange chromosomes with the B-chromosome centromere, are subject to non-disjunction at the second pollen grain division, with the result that the two male nuclei come to have unequal numbers of B chromosomes (Roman, 1947). These two unlike male nuclei have different probabilities of fertilising the egg in the embryo-sac, the one with the greater number of $B$ chromosomes having the greater chance of fertilising the egg (Roman, I948). As a consequence of these two factors, the progeny of maize plants with $\mathrm{B}$ chromosomes tend to have higher mean numbers of B chromosomes than do their parents (Randolph, 1941). Roman (1948) has observed differences in rate of mitotic non-disjunction in the pollen grains between the $\mathrm{B}^{4}$ and $\mathrm{B}^{9}$ interchanged chromosomes in TB-4 $a$ and TB-9 $b$ respectively.

Blackwood (1956) has also shown that when different maize plants are compared there is evidence that the probabilities of nondisjunction in the second pollen grain division and perhaps of preferential fertilisation differ from one strain to another. This is shown by the different progeny means and different progeny distributions of B-chromosome numbers obtained from different parent plants with the same numbers of $B$ chromosomes. The problem is to make estimates of the magnitude of these two effects, so that they may be compared in different sets of data.

The most extensive data available concern crosses of the type $0 \times 2$ B, where only the pollen parent had B chromosomes. Suppose, in a plant with $2 \mathrm{~B}$ chromosomes the frequencies of cells (young pollen grains) with o, I and $2 \mathrm{Bs}$ are $a, b$ and $c$ respectively, immediately after the completion of meiosis. The sum, $b+2 c$, may differ from unity as a result of loss or gain of B chromosomes through errors of movement or reproduction during meiosis, and presumably during preceding mitoses. Available data (Blackwood, r956, table 3) show, amongst $55^{\circ}$ postmeiotic cells, 39 with o $\mathrm{B}, 45^{8}$ with I B and 53 with $2 \mathrm{~B}$, the mean being $\mathrm{I} \cdot 025$ per cell. These values will be used for estimates of $a, b$ and $c$.

If $x$ is the probability that any B chromosome will undergo nondisjunction at the second pollen grain mitosis, and if the probabilities are independent for two B chromosomes present in the same pollen grain, the frequencies of B-chromosome distribution to the male cells of the pollen grains may be written down. However, before doing so, preliminary consideration must be given to the question of whether there is a preferred spindle pole to which the non-disjunctional B 
chromatids pass. If there were, two non-disjunctional B chromosomes would always produce a $4: 0$ distribution. If, however, there were no preferred spindle pole, a $2: 2$ distribution would be produced in half of the cases of double non-disjunction. These alternatives, which respectively involve polarised and random segregation at the

TABLE I

Distribution of $B$ chromosomes to the male nuclei following the second pollen grain division

\begin{tabular}{|c|c|c|}
\hline \multirow{2}{*}{ Distribution } & \multicolumn{2}{|c|}{ Frequency } \\
\hline & Polarised segregation & Random segregation \\
\hline $\begin{array}{l}0+0 \\
1+1 \\
2+0 \\
2+2 \\
3+1 \\
4+0\end{array}$ & $\begin{array}{l}a \\
b(\mathrm{I}-x) \\
b x \\
c(1-x)^{2} \\
2 c x(\mathrm{I}-x) \\
c x^{2}\end{array}$ & $\begin{array}{l}a \\
b(\mathrm{I}-x) \\
b x \\
c(\mathrm{I}-x)^{2}+\frac{1}{2} c x^{2} \\
2 c x(\mathrm{I}-x) \\
\frac{1}{2} c x^{2}\end{array}$ \\
\hline
\end{tabular}

second pollen grain division, lead to somewhat different expectations (table I).

Preferential fertilisation can arise only from the third, fifth and sixth of these distributions. Suppose that the chance of fertilisation of the egg by the male nucleus with the larger number of B chromosomes is $y$, and that this chance is independent of the differential

TABLE 2

Proportions of progeny with different numbers of $B$ chromosomes from $o \times 2 B$ crosses

\begin{tabular}{|c|c|c|}
\hline \multirow{2}{*}{$\begin{array}{l}\text { Number of B } \\
\text { chromosomes }\end{array}$} & \multicolumn{2}{|c|}{ Expectations } \\
\hline & Polarised segregation & Random segregation \\
\hline o & $a+x(\mathrm{I}-y)(b+c x)$ & $a+x(\mathrm{I}-y)\left(b+\frac{c x}{0}\right)$ \\
\hline I & $(\mathrm{I}-x)[b+2 c x(\mathrm{I}-y)]$ & $(\mathrm{I}-x)[b+2 c x(\mathrm{I}-y)]$ \\
\hline 2 & $b x y+c(1-x)^{2}$ & $b x y+c-2 c x+\frac{3 c x^{2}}{2}$ \\
\hline $\begin{array}{l}3 \\
4\end{array}$ & $\begin{array}{l}2 c x y(1-x) \\
c x^{2} y\end{array}$ & $\begin{array}{l}2 \operatorname{cxy}(\mathrm{I}-x) \\
\frac{1}{2} c x^{2} y\end{array}$ \\
\hline
\end{tabular}

number of $\mathrm{B}$ chromosomes. Then the progeny of a $0 \times 2 \mathrm{~B}$ cross will have plants with from none to four $B$ chromosomes with the expectations given in table 2.

It will be noticed that unless $x$ is greater than zero and $y$ is greater than a half, the mean number of $\mathrm{B}$ chromosomes in the progeny cannot exceed the mean number in the parents. 
It is now possible to obtain maximum likelihood estimates of $x$ and $y$ for any particular set of data. This is most simply done by

TABLE 3

Observed and expected frequencies of $B$ chromosomes in the progeny of $o \times 2 B$ crosses. The expectations are computed from the estimates of non-disjunction and of differential fertilisation extracted from the data

(1) Data of Blackwood (1956)

\begin{tabular}{|c|r|r|r|}
\hline \multirow{3}{*}{$\begin{array}{c}\text { Number of } \\
\text { B's }\end{array}$} & \multirow{2}{*}{ Observed } & \multicolumn{2}{|c|}{ Expected } \\
\cline { 3 - 4 } & & Polarised segregation & Random segregation \\
\hline & & & \\
\hline 0 & 16 & $16 \cdot 2547$ & $16 \cdot 1388$ \\
1 & 8 & $6 \cdot 9036$ & $6 \cdot 7390$ \\
2 & 50 & $60 \cdot 2588$ & $63 \cdot 7480$ \\
$1 \cdot 2017$ \\
3
\end{tabular}

(2) Data of Blackwood (1956)

\begin{tabular}{|c|c|c|c|}
\hline \multirow{3}{*}{$\begin{array}{c}\text { Number of } \\
\text { B's }\end{array}$} & \multirow{2}{*}{ Observed } & \multicolumn{2}{|c|}{ Expected } \\
\cline { 3 - 4 } & & Polarised segregation & Random segregation \\
\hline & & & \\
\hline & & $27 \cdot 4614$ & $27 \cdot 6473$ \\
1 & 47 & $46 \cdot 4073$ & $45 \cdot 5429$ \\
2 & 66 & $69 \cdot 5488$ & $72 \cdot 8175$ \\
3 & 5 & $5 \cdot 5168$ & $5 \cdot 4206$ \\
4 & 8 & $5 \cdot 075^{8}$ & $2 \cdot 5717$ \\
\hline \multicolumn{2}{|c|}{$\chi^{2}$ for 2 d.f. } & $1 \cdot 9756$ & $12 \cdot 2766$ \\
\hline
\end{tabular}

(3) Data of Randolph (1941)

\begin{tabular}{|c|c|c|c|}
\hline \multirow{2}{*}{$\begin{array}{c}\text { Number of } \\
\text { B's }\end{array}$} & Observed & \multicolumn{2}{|c|}{ Expected } \\
\cline { 2 - 3 } & & Polarised segregation & Random segregation \\
\hline 0 & 22 & $22 \cdot 0022$ & $\begin{array}{r}16 \cdot 7169 \\
42 \cdot 0218 \\
2 \cdot 2613\end{array}$ \\
2 & 37 & $\begin{array}{r}349530 \\
4 \cdot 044^{2}\end{array}$ & $2 \cdot 3000$ \\
\hline 4 & 2 & $1 \cdot 1536$ & \\
\hline
\end{tabular}

utilising Fisher's (1946) method of scores, and iteration after commencing with trial values. The parameters have been estimated for 
three sets of $0 \times 2 \mathrm{~B}$ data (table 3 ) with the results summarised $\mathrm{i}$ : table 4. The values of $a, b$ and $c$ obtained by Blackwood (I956) given above, have been used for all three sets of data. It is an assumption that the same initial post-meiotic frequency distributions hold exactly for all, but it is probably not very far from being correct. It would be asking too much of the data to extract two more parameters from them.

It is clear that the frequency of non-disjunction of the B chromosomes is different for each set of data, the chance that any two could be alike being less than $0^{\circ}$ or. The only uncertainty is that Randolph's data are theoretically compatible with a value of $x$ less than unity; but even making an allowance for this, the probability that the value of $x$ could be the same as in Blackwood ( $I$ ) is not greater than 0.01 .

The probabilities of differential fertilisation could be the same for all three sets of data, though the values for Blackwood (I) and Randolph have only a small probability (between 0.02 and 0.03 )

TABLE 4

Estimates of genetic parameters of $B$ chromosomes

\begin{tabular}{|c|c|c|c|}
\hline Source of data & $\begin{array}{c}\text { Mode of pollen } \\
\text { grain segregation }\end{array}$ & $\begin{array}{c}\text { Frequency of } \\
\text { non-disjunction } \\
(x)\end{array}$ & $\begin{array}{c}\text { Frequency of } \\
\text { preferential } \\
\text { fertilisation } \\
(y)\end{array}$ \\
\hline Blackwood (1) & Polarised & $0.9113 \pm 0.0301$ & $0.8716 \pm 0.0473$ \\
Blackwood (2) & Random & $0.9135 \pm 0.0297$ & $0.8671 \pm 0.0494$ \\
Randolph & Polarised & $0.6478 \pm 0.0419$ & $0.8149 \pm 0.0499$ \\
& Random & $0.6547 \pm 0.0419$ & $0.8082 \pm 0.0513$ \\
& Polarised & 1 & $0.6881 \pm 0.0662$ \\
& Random & 1 & $0.7694 \pm 0.0648$ \\
\hline
\end{tabular}

of being the same. The differences between Blackwood's two sets of data are ascribable wholly to differences in the rates of non-disjunction during the second pollen grain division. If it is assumed, as may well be true, that there is no real variability in the frequency of differential fertilisation, a weighted mean value for all three sets of data may be calculated using the formula $\Sigma\left(y . \mathrm{I}_{y}\right) \div \Sigma \mathrm{I}_{y}$ where $\mathrm{I}_{y}$ is the information about $y$. The mean value is $0.8115 \pm 0.0307$ for polarised segregation or $0.8227 \pm 0.0312$ for random segregation.

If a comparison is made between the observed frequencies of progeny with different numbers of $\mathrm{B}$ chromosomes and the expected frequencies calculated using the estimates of $x$ and $y$ obtained above, better agreements are found with the expectations calculated on the assumption of polarised non-disjunction at the second pollen grain division (see table 3 ).

Roman (I948) has data for two different B-A interchange chromosomes, for whose behaviour the same two parameters may be estimated. In such interchanges the $\mathrm{B}^{\mathrm{A}}$ chromosome, namely the one with the 
B-chromosome centromere, may undergo non-disjunction at the second pollen grain division with a frequency $x$, giving two male nuclei respectively with $2 \mathrm{~B}^{\mathrm{A}}$ and o $\mathrm{B}^{\mathrm{A}}$ chromosomes. The hyperploid gamete preferentially fertilises the egg with a frequency $y$. Thus the progeny of a normal $\times B^{A}$ cross are of three types with respect to the $\mathrm{B}^{\mathrm{A}}$ chromosomes and may be classified by suitable genetic tests (table 5). In the data quoted, a few progeny, obviously the result of heterofertilisation, have been omitted from the observations used for analysis; the 9 Type III individuals in the TB-gb data could also belong in this category. The estimates of $x$ and $y$, also given in table 5, show, as Roman has reported, that the rates of non-disjunction at the second pollen grain division are distinctly and significantly different for $\mathrm{B}^{4 a}$ and $\mathrm{B}^{9 b}$. However, contrary to Roman's implication (1948, p. 41, para. 2), the frequency of preferential fertilisation is

TABLE 5

Expectations and data for $B^{\mathrm{A}}$ interchange chromosomes in $O \times B^{\mathrm{A}}$ crosses

(Data of Roman, 1948)

\begin{tabular}{|c|c|c|c|c|}
\hline \multirow{2}{*}{ Type } & \multirow{2}{*}{$\begin{array}{c}\text { Embryo } \\
\text { constitution }\end{array}$} & \multirow{2}{*}{$\begin{array}{l}\text { Expected } \\
\text { frequencies }\end{array}$} & \multicolumn{2}{|c|}{ Observed frequencies } \\
\hline & & & TB- $4 a$ & TB- $9 b$ \\
\hline \multirow[t]{2}{*}{$\begin{array}{r}\text { I } \\
\text { II } \\
\text { III }\end{array}$} & \multirow[t]{2}{*}{$\begin{array}{l}0 \mathrm{BA} \\
2 \mathrm{BA} \\
\text { I BA }\end{array}$} & $\begin{array}{c}x(\mathrm{r}-y) \\
x y \\
(\mathrm{r}-x)\end{array}$ & $\begin{array}{l}152 \\
382 \\
\text { I } 24\end{array}$ & $\begin{array}{r}160 \\
327 \\
9\end{array}$ \\
\hline & & Totals & $65^{8}$ & 469 \\
\hline & $\begin{array}{l}\text { ates of } x \\
\text { ates of } y\end{array}$ & . & $\begin{array}{l}0.8116 \text { 土0.0152 } \\
0.7154 \text { 土0.0195 }\end{array}$ & $\begin{array}{l}0.9819 \pm 0.0019 \\
0.6715 \pm 0.0213\end{array}$ \\
\hline
\end{tabular}

not significantly greater in $\mathrm{B}^{4 a}$ than in $\mathrm{B}^{9 b}$. The difference $(0.0439)$ is only 1.519 times its standard error $(0.0289)$, so that $P$ is very nearly $0 \cdot 13$.

\section{DISCUSSION}

There are clear differences between the rates of non-disjunction of B chromosomes and of B-A interchange chromosomes at the second division in the pollen grain in different stocks of maize. However, there is no evidence to show whether the differences are due to innate differences between different $\mathrm{B}$ and $\mathrm{B}^{\mathrm{A}}$ chromosomes or to general differences in the genotypes, residing chiefly in the A chromosomes. Roman (1950) has observed an absence of non-disjunction of $\mathrm{B}^{4}$ chromosomes in unbalanced pollen grains which have a $\mathrm{B}^{4}$ chromosome and a whole chromosome 4 , but lack the $4^{\mathrm{B}}$ chromosome. It was unknown whether the effect was due to the duplication of the distal part of the short arm of chromosome 4 or to the deficiency of the distal part of the $\mathrm{B}$ chromosome present in the $4^{\mathrm{B}}$ chromosome. 
Better agreement with experimental data is found if calculations of expected frequencies are made on the assumption of polarised non-disjunction at the second pollen grain division. If two nondisjunctional $\mathrm{B}$ chromosomes pass always to one spindle pole at P.G. II, it is possible that this division is specifically oriented so that the non-disjunctional B chromosomes, whether one or two, always pass to a specific spindle pole. It is possible that the axis of this division is in line with the axis of the first pollen grain division and that the B chromosomes pass to the outer spindle pole. Roman (1948) has previously suggested, as a possible cause of preferential fertilisation, a specific orientation of the deficient and hyperploid gametes within the pollen grain or at some time prior to fertilisation. The polarised segregation would lead to one of the male nuclei having a positional advantage over the other in respect to union with the egg, and it is particularly attractive to have one hypothesis uniting the two effects.

Presumably the non-disjunction is an interaction between the $\mathrm{B}$ chromosomes and a gradient of organisation within the pollen grain. The intensity of the effect may be expected to vary accordingly as the genotype controls the gradient ; it is possible, also, that different B chromosomes might respond differently to the same gradient.

It is less easy to see how preferential fertilisation could be caused to vary. This might depend upon the degree to which the specific orientation of the two male nuclei, established in the pollen grain, was preserved or disturbed in the germination of the grain and during the growth of the pollen tube. However, the evidence for variation in the attribute of preferential fertilisation is not very strong.

In the estimates made above, preferential fertilisation is shown by values of $y$ which are significantly greater than 0.5 . This effect is of course manifested only in respect of those pollen grains whose male nuclei differ in their content of $\mathbf{B}$ chromosomes. If a coefficient of preferential fertilisation were needed, perhaps the most convenient would be $(2 y-1)$, the difference between $y$ and $(I-y)$. The variance of this coefficient would be twice the variance of $y$. The values for the three sets of data are 0.7432 for Blackwood's (I), 0.6298 for Blackwood's (2) and 0.3762 for Randolph's.

\section{SUMMARY}

Estimates have been made of the rates of non-disjunction of $B$ chromosomes in maize at the second pollen grain division and of preferential fertilisation of the egg by the male gamete with the larger number of chromosomes. The rates of non-disjunction vary between different stocks, but there is no definite evidence that preferential fertilisation varies significantly. There is a strong probability that the second pollen grain division is polarised and a possibility that the resulting arrangement of the two male gametes determines preferential fertilisation. 
This work was carried out in the Department of Genetics in the University of Adelaide.

\section{REFERENCES}

BLACKWOOD, M. 1956. The inheritance of B chromosomes in Zea mays. Heredity, IO, 353-366.

FISHER, R. A. 1946. A system of scoring linkage data, with special reference to the pied factors in mice. Amer. Nat., 80, 568-578.

RANDOLPH, L. F. I941. Genetic characteristics of the B-chromosomes in maize. Genetics, 26, 608-631.

ROMAN, H. 1947. Mitotic non-disjunction in the case of interchanges involving the B-type chromosome in maize. Genetics, 32, 391-409.

roman, H. 1948. Directed fertilisation in maize. Proc. Nat. Acad. Sci. U.S., 34, 36-42.

RoMAN, H. 1950. Factors affecting mitotic non-disjunction in maize. Genetics, 35,132 . 